\title{
Review
}

\section{Immune thrombocytopenia in children with reference to low- income countries}

\author{
A. Rehman'
}

$$
\text { عقص الصفيحات المناعي لدى الأطفال في البلدان المنخفضة الدخل }
$$

الخلاصـة: نقص الصفيحات المناعي هو اضطراب حميد يزول تلقائياً. والمعطيات شحيحة حول حالة هذا

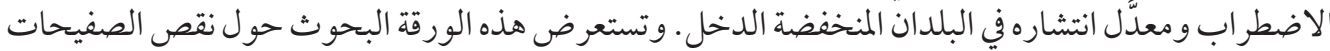

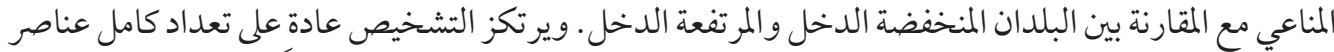

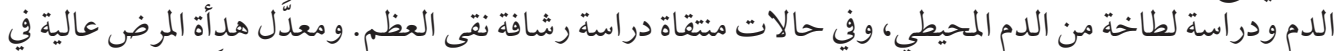

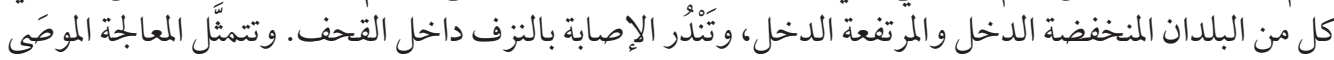

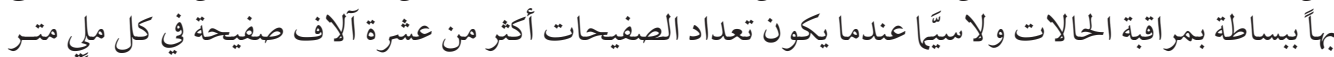

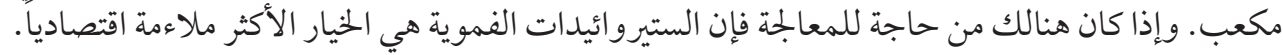

ABSTRACT Immune thrombocytopenia is a benign and self-limiting disorder. Data about the condition and its incidence from low-income countries is limited. This paper reviews the research about immune thrombocytopenia, comparing low- and high-income countries. Diagnosis is usually based on complete blood count and peripheral smear and, in selected cases, bone marrow aspiration. The disease has a high remission rate both in high- and low-income countries and intracranial haemorrhage is rare. The recommended treatment is simply observation of cases, especially when the platelet count is $>10000 / \mathrm{mm}^{3}$. If drug therapy is required, oral steroids are the most economical choice.

\section{Thrombopénie immunologique chez les enfants : le cas des pays à faible revenu}

RÉSUMÉ La thrombopénie immunologique est un trouble bénin et spontanément résolutif. Les données sur cette maladie et sur son incidence dans les pays à faible revenu sont limitées. Le présent article fait le point sur la recherche dans ce domaine, en comparant les pays à revenu faible et élevé. Le diagnostic repose généralement sur la numération sanguine complète et le frottis sanguin périphérique et, dans certains cas, sur la ponction médullaire. Le taux de rémission de la maladie est important dans les pays à revenu élevé et à faible revenu, et les hémorragies intracrâniennes sont rares. Le traitement recommandé est la simple observation des cas, notamment lorsque le nombre de plaquettes est supérieur à $10000 / \mathrm{mm}$. Si un traitement est nécessaire, les stéroïdes par voie orale constituent la solution la plus économique.

\footnotetext{
${ }^{1}$ Paediatric Unit-II, Bahawal Victoria Hospital, Bahawalpur, Pakistan (Correspondence to A. Rehman: drarehman100@yahoo.com).
}

Received: 15/07/06; accepted: 18/12/06

المجلة الصحية لشرق المتوسط، منظمة الصحة العالمية، المجلد الخامس عشر، العدد ب، 9 ب. 


\section{Introduction}

According to 2005 World Bank data there are 54 low-income countries in the world (i.e. gross national income US\$ 875 or less per capita) [1]. Providing equitable and cost-effective evidence-based management of noncommunicable diseases is a major challenge in such low-resource settings $[1,2]$. One such disease in children is immune thrombocytopenia (also called immune thrombocytopenic purpura or ITP), which is the most common acquired bleeding illness in children [3]. There is substantial discrepancy in the treatment of ITP among clinicians, even among high-income countries, who are likely to over-treat $[4,5]$. The treatment costs can be as high as US\$ 4700 per patient in high-income countries in spite of the benign nature of ITP [6].

The purpose of this paper is to review the research about ITP with a focus on lowincome countries and comparison of the data from high-income countries, to help in designing cost-effective ways to manage the disease in low-income settings.

\section{Definition and pathogenesis}

ITP in children is usually a benign and selflimiting disorder. The American Society of Hematology defines it as an isolated thrombocytopenia with clinically no apparent associated conditions or no other cause of thrombocytopenia, such as HIV infection, systemic lupus erythematosus, lymphoproliferative disorders, myelodysplasia, agammaglobulinaemia or hypogammaglobulinaemia, drug-induced thrombocytopenia, alloimmune thrombocytopenia or congenital/hereditary non-immune thrombocytopenia [7]. Chronic ITP is the term used if the disease persists for over 6 months [8].

It is caused by an inappropriate response of the immune system usually following a viral infection or immunization. In ITP the autoantibodies are directed against the individual's own platelets, resulting in increased Fc-mediated platelet destruction by macrophages in the reticuloendothelial system [3].

\section{Incidence and epidemiology}

The incidence of the disease in high-income countries is about 3-10 per 100000 children per year below 16 years of age $[8,9]$. The exact incidence of the disease in lowincome countries is unknown. A study in Nigeria showed that the overall prevalence was $0.005 \%$ of total hospital cases [10]. The percentage of children admitted due to ITP during the years 2003 and 2004 to the Department of Haematology/Oncology at the Children's Hospital in Lahore, Pakistan was $4.8 \%$, out of which $69 \%$ cases were acute ITP [11]. The disease has rarely been described in Africa, which may be due to genetic or environmental factors, or it may simply be that physicians overlook this disease when making a diagnosis $[12,13]$.

Kühne et al., from a high-income country, reported a history of infection preceding the disease in $60.2 \%$ of cases [14]. In high-income countries it may also follow a childhood vaccination [15]. Kühne et al., comparing Vietnamese with German and Swiss children found significant differences in history of infection preceding the onset of ITP between the Asian and European cohorts [16]. ITP seems to be characterized by a seasonal occurrence usually after acute viral infections $[11,17,18]$.

\section{Clinical features}

The usual age range for presentation of ITP reported from Switzerland was 1-10 years [14]. Studies from low-income countries show an age range of $1.2-14$ years

المجلة الصحية لشرق المتوسط، منظمة الصحة العالمية، المجلد الخامس عشر، العدد ؟، 9 + · 
$[11,19,20]$. Kühne et al. did not find any difference in age or sex of presentation between the Asian and European cohorts [16]. In high-income countries both sexes are equally affected, whereas in the limited studies reported in low-income counties the female:male ratio varies from 2:3 to $1.9: 1$ [11,18-21].

The classical features in children from high-income countries include a sudden onset of excessive bruising, petechiae and or mucous membrane bleeding 1-4 weeks following a viral infection [3]. Fever, lethargy, weight loss, bone pains, joint pains, pallor, lymphadenopathy and hepatosplenomegaly are characteristically absent. Minimal splenomegaly occurs in about $5 \%-12 \%$ of symptomatic children $[22,23]$ but marked splenomegaly is typically absent. The presentation from low-income countries is very similar [11,18-20]. Anaemia [24], splenomegaly and lymphadenopathy may be more common in low-income countries due to the high prevalence of nutritional deficiencies and infections, but no studies are available to confirm this.

\section{Diagnosis}

It is recommended by the American Society of Hematology that in a typical case only complete blood count (CBC) and examination of the peripheral blood smear are essential for the diagnosis [7]. The CBC demonstrates isolated and often profound thrombocytopenia. Platelets are normal or large but not giant in size with normal red blood cell morphology and normal white blood cell count and morphology. A study in Nigeria showed that $72 \%$ of ITP cases were severely anaemic requiring blood transfusion [10], which might be due to the high prevalence of iron deficiency in lowincome countries [25] and associated blood loss from the disease process.
It has been established from studies in high-income countries that bone-marrow aspiration is only indicated if there is any doubt about the diagnosis [26,27], if steroids are to be given $[4,5]$ or in infants with Down syndrome in whom thrombocytopenia may signal the development of megakaryoblastic leukaemia [28]. Other studies in high-income countries have shown that bone-marrow aspiration is not necessary in typical cases even if steroids are to be used [29-31].

Hassan et al. from Pakistan studied bonemarrow aspiration in children with ITP and found that, in addition to typical changes in megakaryocytic series in the bone marrow, a concomitant iron deficiency as well as mild to moderate megaloblastic changes were seen [21]. Kalim et al. from Pakistan concluded that it was necessary to do bonemarrow aspiration in every child with a typical presentation of ITP [19].

The American Society of Hematology does not recommend investigations such as antinuclear antibody, direct antiglobin antibody, HIV, mean platelet volume or reticulocyte counts for the routine work-up of acute ITP as these are not cost-effective and do not improve the diagnosis [7].

\section{Differential diagnosis}

There is long list of causes of thrombocytopenia in children both in high and low-income countries, such as congenital thrombocytopenias, acute leukaemia, aplastic anaemia and myelodysplastic syndromes, haemolytic-uraemic syndrome, and drugs such as quinine, cephalosporins and rifampicin. Infections that are endemic in certain areas of low-income countries, such as dengue fever [32], brucellosis [33], leishmaniasis [34], malaria, HIV [35] and viral hepatitis [36], can cause thrombocytopenia.

المجلة الصحية لشرق المتوسط، منظمة الصحة العالمية، المجلد الخنامس عشر، العدد ب، 9 +. 
All the above-mentioned conditions have other characteristic clinical features in addition to thrombocytopenia. Jan studied the etiology of thrombocytopenia in children aged under 12 years at Peshawar, Pakistan, and found acute ITP was responsible for $32 \%$ of cases, aplastic anaemia for $24 \%$, acute lymphoblastic leukaemia for $22 \%$, lymphoma for $4 \%$, haemolytic-uraemic syndrome for $4 \%$, megakaryocytic hypoplasia for $3 \%$, drug-induced thrombocytopenia for $3 \%$, hypersplenism for $3 \%$, neonatal thrombocytopenia for $2 \%$, Plasmodium falciparum malaria for $2 \%$ and leishmaniasis for $1 \%$ cases of thrombocytopenia [37]. Ali et al. found that malaria was responsible for $27.0 \%$, megaloblastic anaemia for $23.0 \%$, bacterial infections for $13.5 \%$, leukaemia for $13.5 \%$, neonatal thrombocytopenia for $9.5 \%$, ITP for $2.7 \%$, disseminated intravascular coagulation for $1.4 \%$, aplastic anaemia for $1.4 \%$ and upper respiratory viral infections for $8 \%$ of cases [38].

\section{Outcome}

In high-income countries $75 \%-90 \%$ of cases go into complete remission irrespective of the treatment given [39-41] and the reported mortality in ITP is $0.1 \%-0.5 \%[23,42]$. In low-income countries the remission rate within 6 months is about $44 \%-100 \%$, irrespective of treatment $[11,19-21,43]$. Female sex, insidious onset of the disease and preceding history of viral infection were features related to an increased chance of development of chronic ITP [18]. It is not generally life-threatening.

\section{Intracranial haemorrhage \& ITP}

Intracranial haemorrhage is extremely rare in ITP. The majority of intracranial haemorrhage events in high-income countries do not occur during the first few days after diagnosis. Intracranial haemorrhage has occurred in children even on treatment [44] and has no correlation with either the severity of bleeding symptoms or the platelet count [45].

Arya et al. from India reported intracranial haemorrhage in 8 cases $(3.3 \%)$; 6 of these children had chronic ITP at the time of presentation with intracranial haemorrhage [46]. Only 2 children presented within 3 months of diagnosis of ITP. The mean interval from the onset of ITP to the development of intracranial haemorrhage was 1.9 months in these 2 cases with high mortality, despite the use of immunoglobulin therapy or highdose corticosteroids in these patients. Other studies from low-income countries have not reported any cases of intracranial haemorrhage $[11,37,43]$.

\section{Management}

There is a need to explain the clinical course of ITP to the parents of the affected child. It is important to restrict motor activities temporarily, to avoid contact sports, to avoid some procedures (e.g. dental extractions) and not to use certain drugs such as aspirin and ibuprofen which may worsen bleeding symptoms. It is advisable to attend the hospital in the case of an accident.

There is substantial discrepancy in the management of ITP among published guidelines from high-income countries [7,47]. According to the American Society of Hematology the best treatment is observation, except when the platelet count is $<20000 /$ $\mathrm{mm}^{3}$ with significant mucous membrane bleeding or $<10000 / \mathrm{mm}^{3}$ with minor purpura [7]. Treatments used for acute ITP include intravenous immunoglobulin (IV Ig), steroids and anti-D immunoglobulin (anti-D Ig). The role of drugs is controver- 
sial. These drugs only increase the platelet count but do not alter the clinical course of the disease [7].

The exact mechanism of action of IV Ig is unknown. IV Ig may be involved in occupying the Fc-receptors on reticuloendothelial cells, resulting in survival of the opsonized platelets [23]. Another mechanism of action may be the presence of anti-idiotypic antibodies in the pooled IV Ig preparations which bind to circulating autoantibodies, rendering them ineffective for platelet opsonins, and may also suppress the B-cells that produce the offending autoantibodies [23].

The mechanism of action of glucocorticosteroids is thought to be multifactorial. They can increase vascular stability and increase platelet survival; an effect attributed to both decreased production of antiplatelet antibodies and decreased clearance of opsonized platelets [48].

The mechanism of action of anti-D Ig is said to be that anti-red blood cell antibody complexes bind to macrophage Fc-receptors and interfere with platelet destruction.

The limited number of studies done in low-income countries have shown that children with severe thrombocytopenia, particularly when the platelet count is between 10000 and $20000 / \mathrm{mm}^{3}$ [19,49], can safely be managed with "watchful waiting" without any specific therapeutic intervention. Chandra et al. from India compared the bleeding manifestations when the platelet count was $<10000 / \mathrm{mm}^{3}$ and those between $10000-20000 / \mathrm{mm}^{3}$ and showed that in $76.6 \%$ of episodes with counts $>10000 /$ $\mathrm{mm}^{3}$ there was no or only cutaneous bleeding compared to $59.5 \%$ episodes of bleeding when the platelet count was $<10000 / \mathrm{mm}^{3}$ $(P<0.05)[49]$. Kalim et al. from Pakistan also advised a wait-and-see policy [19].

IV Ig is considered as the drug of choice according to the American Society of He- matology, if needed [7]. A meta-analysis of corticosteroids versus IV Ig for the treatment of acute ITP showed that children treated with corticosteroids were $26 \%$ less likely to have a platelet count $>20000 / \mathrm{mm}^{3}$ after 48 hours of therapy when compared with children treated with IV Ig [50]. Adverse effects of IV Ig are common (in 15\% to $75 \%$ of cases) but generally mild. However, IV Ig is costly and may not be easily available even in high-income countries [51,52], as a result of growing indications for its use [53]. Hord and Grossman found that the cost of hospitalization was 3.5 times greater for patients on IV Ig as compared to steroids [54]. The current quoted cost in Australia of imported IV Ig is AUD 100 per gram [53]. The situation in low-income countries is worse; e.g. in India the price of IV Ig is US\$ 48-58 per gram, meaning that the cost of treating a child weighing $30 \mathrm{~kg}$ is about US\$2880-3480 [55]. Another treatment is anti-D Ig which is generally not as longlived as IV Ig and cannot be used in Rh-D negative people. Furthrmore, it aggravates anaemia, is also expensive and is not easily available in low-income countries.

O'Brien et al. from the United States of America analysed the costs and found that steroids are the drug of choice in low-income countries, if any drug is to be used, due to the high cost and problems in availability of IV Ig and anti-D Ig [56]. Uncontrolled studies done in low-income countries show that steroids are effective $[10,13,19,20]$. Although short courses of steroids in childhood ITP are not commonly associated with the side-effects of weight gain, sleep disturbance, hypertension and hyperglycaemia, careful monitoring is still needed. One very important issue is reactivation of tuberculosis (TB) while on steroids, as TB is endemic in many low-income countries. It is important to observe patients with evidence of previous infection with TB or who

المجلة الصحية لشرق المتو سط، منظمة الصحة العالمية، المجلد الخامس عشر، العدد ب، 9 +. 
live in areas where TB is endemic, for signs of reactivation of disease [57]. A recent meta-analysis of 6602 patients concluded that although TB occurred more frequently in patients receiving steroids than in the placebo group, the difference was not statistically significant [58]. It is better to rule out TB prior to starting steroids, if possible. Another drawback is that steroids may hide leukaemia, but it is very rare for a child to present with isolated thrombocytopenia in leukaemia.

The dose regimens include oral prednisolone $2 \mathrm{mg} / \mathrm{kg} /$ day or $60 \mathrm{mg} / \mathrm{m}^{2} /$ day for 14 days, followed by a tapering dose and discontinuation on day $21[59]$ or $4 \mathrm{mg} / \mathrm{kg} /$ day in 3 divided doses for 7 days, followed by a $50 \%$ reduction in the dose in the second week, and then by a tapering dose and discontinuation on day 21 [60].

\section{Conclusion}

The data about ITP from poor countries, although very limited, resemble that from high-income countries. The best treatment is observation, except in cases with platelet count $<10000 / \mathrm{mm}^{3}$, where steroids may be tried without any definite benefit. There is an urgent need to develop an ITP registry system to study the disease and to develop uniform cost-effective management protocols for the disease.

\section{References}

1. The World Bank [website] (http://www. worldbank.org/, accessed 20 January 2009).

2. Townsend Centre for International Poverty Research[website] (http://www.bris.ac.uk/ poverty/child\%20poverty.html\#abpov, accessed 20 January 2009).

3. Rehman A. Acute immune thrombocytopenic purpura in children. Turkish journal of hematology, 2007, 28:41-8.

4. Bolton-Maggs $\mathrm{PH}$, Moon I. Assessment of UK practice for management of acute childhood idiopathic thrombocytopenic purpura against published guidelines. Lancet, 1997, 350:620-3.

5. Vesely $\mathbf{S}$ et al. Self reported diagnostic and management strategies in childhood idiopathic thrombocytopenic purpura: results of a survey of practicing pediatric hematology-oncology specialists. Journal of pediatric hematology/oncology, 2000, 22:55-61.

6. Kumar $\mathrm{M}$ et al. Treatment, outcome, and cost of care in children with idiopathic thrombocytopenic purpura. American journal of hematology, 2005, 78:181-7.

7. George JN et al. Idiopathic thrombocytopenic purpura: a practice guideline developed by explicit methods for the American Society of Hematology. Blood, 1996, 88:3-40.

8. Mattia DD et al. Acute childhood idiopathic thrombocytopenic purpura: AIEOP consensus guidelines for diagnosis and treatment. Haematologica, 2000, 85:420-4.

9, Lilleyman JS. Management of childhood idiopathic thrombocytopenic purpura. British journal of haematology, 1999, 105:871-5.

10. Salawu L, Durosinmi MA. Immune thrombocytopenic purpura: 11-year experience in Ile-Ife, Nigeria. African journal of medicine and medical sciences, 2001, 30:99-103.

11. Ali AS et al. Idiopathic thrombocytopenic purpura-initial illness and subsequent behaviour. Pakistan pediatric journal, 2005, 29(2):93-9. 
12. Gbadoe AD et al. Le purpura thrombopenique idiopathique de l'enfant en Afrique noire: a propos d'un cas au Togo [Idiopathic thrombopenic purpura in a child in black Africa: a case report in Togo]. Santé, 1998, 8:337-41.

13. Rasamoelisoa JM et al. Etude du purpura thrombopenique idiopathique dans deux services pediatriques de la ville d'Antananarivo [Study of idiopathic thrombopenic purpura in two paediatric services of Antananarivo city]. Archives de l'Institut Pasteur de Madagascar, 1999, 65:110-2.

14. Kühne T et al. A prospective comparative study of 2540 infants and children with newly diagnosed idiopathic thrombocytopenic purpura (ITP) from the intercontinental childhood ITP study group. Journal of pediatrics, 2003, 143:605-8.

15. Sanford R, Kimmel MD. Vaccine adverse events: separating myth from reality. American family physician, 2002, 66:2113-20.

16. Kühne $\mathrm{T}$ et al. Ethnicity and environment may affect the phenotype of immune thrombocytopenic purpura in children. Pediatric research, 2000, 48:374-9.

17. Gebauer E, Vijatov G. Idiopatska trombocitopenijska purpura u dece [Idiopathic thrombocytopenic purpura in children]. Medicinski pregled, 1998, 51:127-34.

18. Khan HA, Iftikhar S. Idiopathic thrombocytopenic purpura: experience at Department of Pediatrics, Mayo Hospital, Lahore, 1998-2001. Pakistan journal of pathology, 2002, 13:7-13.

19. Kalim M, Ali L, Khattak AA. Childhood idiopathic thrombocytopenia: clinical profile and management. Journal of Postgraduate Medical Institute, 2005, 19:101-5.

20. Bedri A, Abebe E. Idiopathic thrombocytopenic purpura (ITP) in Ethiopian children: clinical findings and response to therapy. Ethiopian medical journal, 1995, 33(2):75-81.
21. Hassan $\mathrm{K}$ et al. A comparison of clinicohaematological features in children and adults suffering from idiopathic thrombocytopenic purpura. Journal of Pakistan Institute of Medical Sciences, 1993, 4:214-7.

22. Souid A, Sadowitz PD. Acute childhood immune thrombocytopenic purpura. Diagnosis and treatment. Clinical pediatrics, 1995, 34:487-94.

23. Crow $A R$ et al. Mechanisms of action of intravenous immunoglobulin in the treatment of immune thrombocytopenia. Pediatric blood and cancer, 2006, 47(5 Suppl.):710-3.

24. Yip R. The challenge of improving iron nutrition: limitations and potentials of major intervention approaches. European journal of clinical nutrition, 1997, 51:516-24.

25. Paracha $P$ et al. Prevalence of anaemia in semi-urban areas of Peshawar, Pakistan: a challenge for health professionals and policy makers. Journal of the Pakistan Medical Association, 1997, 47(2):49-53.

26. Halperin DS, Doyle JJ. Is bone marrow examination justified in idiopathic thrombocytopenic purpura? American journal of diseases of children, 1988, 142:508-11.

27. Calpin $\mathrm{C}$ et al. Is bone marrow aspiration needed in acute childhood idiopathic thrombocytopenic purpura to rule out leukemia? Archives of pediatrics \& adolescent medicine, 1998, 152:345-7.

28. Zipursky A, Poon A, Doyle J. Leukemia in Down syndrome: a review. Pediatric hematology and oncology, 1992, 9:139-49.

29. Dubansky AS, Boyett JM, Fallette J. Isolated thrombocytopenia in children with acute lymphoblastic leukemia: a rare event in a pediatric oncology group study. Pediatrics, 1989, 84:1068-71.

30. Jubelirer SJ, Harpold R. The role of the bone marrow examination in the diagnosis of immune thrombocytopenic purpura: case series and literature review. Clini-

المجلة الصحية لشرق المتوسط، منظمة الصحة العالمية، المجلد الخامس عشر، العدد با، 9 . · 
cal and applied thrombosis/hemostasis, 2002, 8:73-6.

31. Klaassen RJ et al. Initial bone marrow aspiration in childhood idiopathic thrombocytopenia: decision analysis. Journal of pediatric hematology/oncology, 2001, 23:511-8.

32. Karande $S$ et al. Concurrent outbreak of leptospirosis and dengue in Mumbai, India, 2002. Journal of tropical pediatrics, 2005, 51:174-81.

33. Al-Shamahy HA, Wright SG. A study of 235 cases of human brucellosis in Sana'a, Republic of Yemen. Eastern Mediterranean health journal, 2001, 7:238-46.

34. Kafetzis DA. An overview of paediatric leishmaniasis. Journal of postgraduate medicine, 2003, 49:31-8.

35. Scaradavou A. HIV-related thrombocytopenia. Blood reviews, 2002, 16:73-6.

36. Shenoy R, Nair S, Kamath N. Thrombocytopenia in hepatitis $\mathrm{A}$-an atypical presentation. Journal of tropical pediatrics, 2004, 50:241-4.

37. Jan MA. Thrombocytopenia in children. Journal of Postgraduate Medical Institute, 2004, 18:353-8.

38. Ali $\mathrm{N}$ et al. Thrombocytopenia: analysis of 415 patients. Pakistan journal of pathology, 2004, 15:143-6.

39. Dickerhoff $R$, von Ruecker A. The clinical course of immune thrombocytopenic purpura in children who did not receive intravenous immunoglobulins or sustained prednisone treatment. Journal of pediatrics, 2000, 137:629-32.

40. Gadner H. Management of immune thrombocytopenic purpura in children. Reviews in clinical and experimental haematology, 2001, 5:201-21, discussion 311-2.

41. Ahmed $S$ et al. Prognostic variables in newly diagnosed childhood immune thrombocytopenia. American journal of hematology, 2004, 77:358-62.
42. Moser AM, Shalev H, Kapelushnik J. Anti$D$ exerts a very early response in childhood acute idiopathic thrombocytopenic purpura. Pediatric hematology and oncology, 2002, 19:407-11.

43. Tancabelic J, Stout LA, Wetering J. Acute immune thrombocytopenic purpura in children and adolescents in South $\mathrm{Da}$ kota 1998-2004. South Dakota journal of medicine, 2005, 58:465-8.

44. Butros LJ, Bussel JB. Intracranial hemorrhage in immune thrombocytopenic purpura: a retrospective analysis. Journal of pediatric hematology/oncology, 2003, 25:660-4.

45. Iyori $\mathrm{H}$ et al. Intracranial haemorrhage in children with immune thrombocytopenic purpura. Annals of haematology, 2000, 79:691-5.

46. Arya LS et al. Spontaneous intracranial hemorrhage in children with immune thrombocytopenic purpura. Indian pediatrics, 2002, 39:468-72.

47. Sutor $\mathrm{AH}$ et al. Hämostasiologie: Akute postinfektiöse Immunthrombozytopenie im Kindesalter [Haemostasis: acute postinfection immune thrombocytopenia in infancy. In: Reinhard D et al., eds. Leitlinien Kinderheilkunde und Jugendmedizin [Guidelines for paediatric and adolescent medicine]. Munich, Urban and Fischer, 1999:23-7.

48. Schultz Beardsley D, Nathan DG. Platelet abnormalities in infancy and childhood. In: Nathan DG, Orkin SH, eds. Nathan and Oski's hematology of infancy and childhood. Philadelphia, Saunders, 1998:1585-630.

49. Chandra $\mathrm{J}$ et al. Bleeding manifestations in severely thrombocytopenic children with immune thrombocytopenic purpura. Hematology, 2006, 11:131-3.

50. Beck CE et al. Corticosteroids versus intravenous immune globulin for the treat- 
ment of acute immune thrombocytopenic purpura in children: a systematic review and meta-analysis of randomized controlled trials. Journal of pediatrics, 2005, 147:521-7.

51. Biological product shortages. US Food and Drug Administration [website] (http:// www.fda.gov/cber/shortage/shortage. htm\#cur, accessed 20 January 2009)

52. Boulis A, Goold S, Ubel PA. Responding to the immunoglobulin shortage: a case study. Journal of health politics, policy and law, 2002, 27:977-1000.

53. Review of the use and supply of intravenous immunoglobulins in Australia: a report by the Blood and Blood Products Committee, Australian Health Ministers' Advisory Council. Adelaide, Australian Health Ministry, 2000.

54. Hord JD, Grossman NJ. Intravenous corticosteroids versus intravenous gammaglobulin in the treatment of acute immune thrombocytopenic purpura. Pediatric hematology and oncology, 1993, 10:323-7.

55. What is IVIG or intra venous immunoglobulin? CIDPUSA Foundation [website] (http://www.cidpusa.org./ivig.html, accessed 20 January 2009).
56. O'Brien SH, Ritchey AK, Smith KJ. A cost-utility analysis of treatment for acute childhood idiopathic thrombocytopenic purpura (ITP). Pediatric blood and cancer, 2006, 48(2):173-80.

57. Chrousos GP. Glucocorticoid therapy and Cushing syndrome. In: emedicine, updated on 6 December 2002 (http://www. emedicine.com/, accessed 20 January 2009).

58. Conn HO, Poynard T. Corticosteroids and peptic ulcer: meta-analysis of adverse events during steroid therapy. Journal of internal medicine, 1994, 236:6-9.

59. Buchanan G, Holtkamp C. Prednisone therapy for children with newly diagnosed idiopathic thrombocytopenic purpura. A randomized clinical trial. American journal of pediatric hematology/oncology, 1984, 6:355-61.

60. Blanchette $\vee$ et al. Randomised trial of intravenous immunoglobulin $\mathrm{G}$, intravenous anti-D and oral prednisone in childhood acute immune thrombocytopenic purpura. Lancet, 1994, 344:703-7. 